Article

\title{
Quality Control System for Beer Developed with Monoclonal Antibodies Specific to Barley Lipid Transfer Protein
}

\section{Yukie Murakami-Yamaguchi ${ }^{1}$, Junko Hirose ${ }^{2}$, Kumiko Kizu ${ }^{3}$, Fumiko Okazaki ${ }^{4}$, Wataru Fujii ${ }^{5}$ and Hiroshi Narita ${ }^{4} *$}

1 Kyoto College of Nutritional \& Medical, Setogawa-cho 18, Saga Tenryuji, Ukyo-ku, Kyoto 616-8376, Japan; E-Mail: yukie.yamaguchi@ taiwa.ac.jp

2 Department of Food and Nutrition, School of Human Cultures, The University of Shiga Prefecture, Hassaka-cho 2500, Hikone, Shiga 522-8533, Japan; E-Mail: jhirose@ shc.usp.ac.jp

3 Department of Life and Living, Osaka Seikei College, Aikawa 3-10-62, Higashiyodogawa, Osaka 533-0007, Japan; E-Mail: kizu@osaka-seikei.ac.jp

4 Department of Food and Nutrition, Kyoto Women's University, Kitahiyoshi-cho 35, Imakumano, Higashiyama-ku, Kyoto 605-8501, Japan; E-Mail: k1134201@kyoto-wu.ac.jp

5 Suntory Business Expert Limited, Wakayamadai, Shimamoto-cho, Mishima-gun, Osaka 618-8503, Japan; E-Mail: Wataru_Fujii@suntory.co.jp

* Author to whom correspondence should be addressed; E-Mail: narita@ kyoto-wu.ac.jp; Tel./Fax: +81-75-531-7154.

Received: 17 September 2012; in revised form: 28 September 2012 / Accepted: 9 October 2012 / Published: 16 October 2012

\begin{abstract}
Non-specific lipid transfer protein (LTP) in barley grain reacted with the IgE in sera drawn from food allergy patients. A sandwich-type of enzyme-linked immunosorbent assay (ELISA) was developed with mouse monoclonal antibodies raised against LTP purified with barley flour. This ELISA showed a practical working range of $0.3-3 \mathrm{ng} / \mathrm{mL}$ and no cross-reactivity with wheat, adlay and rye. Using this ELISA, LTP was determined in several types of barley-foods, including fermented foods such as malt vinegar, barleymalt miso and beer. LTP content in beer of the same kind was approximately constant, even if manufacturing factory and production days were different. Not only as a factor of foam formation and stability but also as an allergen, controlling and monitoring of LTP in beer should be considered. Taken together, our LTP-detecting ELISA can be proposed as an appropriate system for the quality control of beer.
\end{abstract}


Keywords: lipid transfer protein; beer; ELISA; food allergy; monoclonal antibody

\section{Introduction}

Non-specific lipid transfer protein (LTP) is an ubiquitous 9-kDa protein widely present in the plant kingdom. Its lipid binding property primary postulates the role of LTP in the intracellular transport of lipids [1,2]. However, it is now known that LTP is synthesized as a precursor with a typical N-terminal signal peptide and the mature LTP is secreted outside the cell $[1,3,4]$. Therefore, the former idea about lipid transportation by LTP has been abandoned. While LTP 2 with a size around 7-kDa is also present as a minor component, we will treat LTP 1 as LTP in this study, hereafter [2]. The highest expression of LTP has been found in peripheral cell layers surrounding aerial organs, associated with the cell wall and cuticle of epidermal tissues. Stress factors, such as drought, cold and high salinity have been described to upregulate the expression of LTP in plants [1,5-7]. Many reports have mentioned the physiological role of LTP in the protective mechanism against the attack of bacteria, fungi and viruses [8-11]. Accordingly, LTP has been classified as pathogenesis-related protein 14 (PR-14) [12].

LTP has been confirmed as to its involvement in the human allergic reaction to fruits, vegetables, nuts, and even pollens [13-17]. LTP is composed of eight cysteine residues forming a network of four disulfide bridges. These disulfide bonds provide stability in the structure of LTP to heat treatment and proteolytic digestion, which is the characteristic feature of food allergen. In addition, the lipid binding domain of LTP also plays an important role in its allergenic property [2,18,19]. Furthermore, LTP is known to be a panallergen according to its highly homologous nature in amino acid sequence and 3D structure among various plants [2,20,21]. Since barley LTP (bLTP) is also resistant to heat treatment and proteolytic digestion, bLTP, as well as protein Z, remains in beer and contributes to foam formation and stability of beer [22,23]. It is noteworthy that LTP performs higher allergenicity than protein $\mathrm{Z}$ according to the result of prick test [15,24,25].

Globally, food manufacturers have faced the growing of consumers' concerns regarding the presence of allergens in their products. Japanese Ministry of Health, Labor and Welfare made the first decision in the world for the mandatory labeling of several foods containing allergenic ingredients in 2002 from the viewpoint of preventing the occurrence of health hazard [26]. Development of the proper analytical method for the determination of allergens in foods is necessary in order to ensure the quality, safety and fair trade of foods for consumers. Enzyme-linked immunosorbent assay (ELISA) is well known, and is widely utilized as a method for determining the presence of specific proteins in processed foods [26]. In this study, we have developed ELISA with monoclonal antibodies (mAbs) specific to bLTP and proposed its application in quality controlling of beer production.

\section{Results and Discussion}

\subsection{Barley Grain LTP}

Barley LTP (bLTP) was purified from commercial barley grain flour by using $\left(\mathrm{NH}_{4}\right)_{2} \mathrm{SO}_{4}$ precipitation, hydrophobic chromatography and cationic exchange chromatography. Corresponding to 
the position on SDS-PAGE, the homogenous protein with a molecular mass about 9-kDa was obtained. To clearly identify whether this protein is bLTP, the N-terminal amino acid sequence of this protein was analyzed. The result showed the eight amino acid sequence LN(X)GQVDS, that was identical to the first eight amino acid sequence of bLTP reported by Douliez et al. [2]. Thus, the purified 9-kDa protein was bLTP, as confirmed by its apparent molecular mass and a part of amino acid sequence (Figure 1). The concentration of purified bLTP was determined by absorbance assay (280 nm) and $\mathrm{DC}^{\mathrm{TM}}$ protein assay [27] using BSA as a standard protein. According to the result of $\mathrm{DC}^{\mathrm{TM}}$ protein assay, concentration of bLTP was three times higher than that determined by measuring absorbance at $280 \mathrm{~nm}\left(\mathrm{E}_{1 \%}=10\right)$. The difference in concentration determined by these two methods might be due to the lack of tryptophan and small amount of tyrosine (three residues) in the amino acid sequence of bLTP. The purified bLTP showed lipid transfer activity measured according to the Paridon's method [28], suggesting no changing in bLTP structure by purification process (data not shown). This pure bLTP, obtained as described, was used here for further investigation.

Figure 1. Deduced amino acid sequences of barley seed and leaf lipid transfer proteins (LTPs) and wheat seed LTP from their nucleotide sequences (NLT1_HORVU, NLT3_HORVU, and NLTA_WHEAT). The blue highlight indicated the homologous amino acid in the alignment of these amino acid sequences.

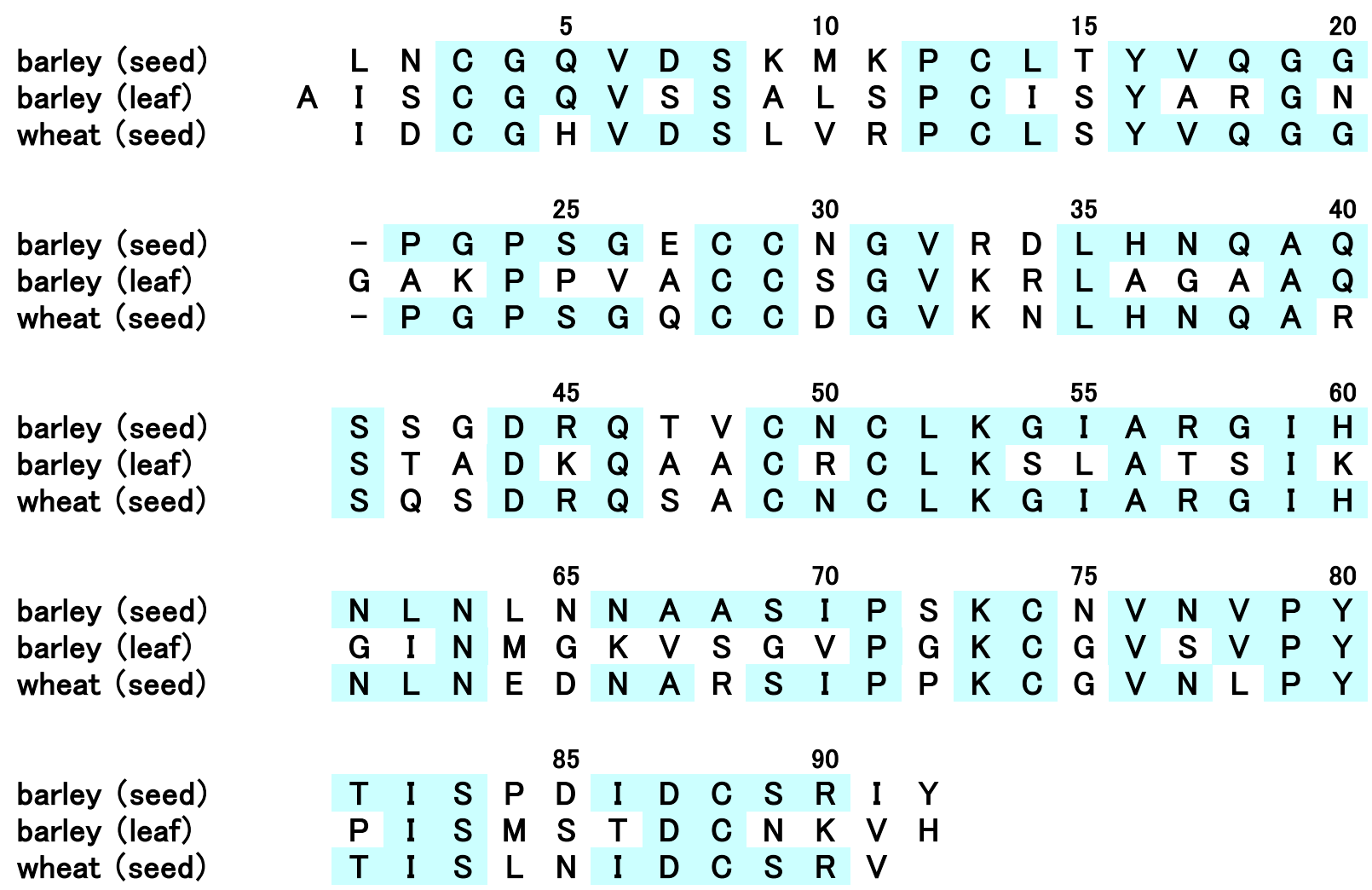

\subsection{Allergenicity of bLTP}

Human sera possessing IgE of barley, wheat, or apple obtained from 10 food allergy patients (Table 1) were tested individually to determine IgE reactivity to bLTP by immunoblotting analysis (Figure 2). The sera No. 5 and 10 showed no reactivity to bLTP in the extract. On the other hand, the high 
reactivity to bLTP in the extract was detected in sera No. 1-4 and 6-9. Despite other protein bands at the molecular mass of 14, 28 and 60-kDa also were present in the extract and showed similar band intensity as that of bLTP on protein staining; a high intensity of the IgE-binding band was only observed at the position of bLTP. This result indicates the importance of bLTP as the major allergen in barley food products. Thus, preventing bLTP contamination in food processing system should be seriously concerned.

Table 1. Characteristics of sera from patients with food allergy.

\begin{tabular}{ccccc}
\hline $\begin{array}{c}\text { Patient } \\
\text { No. }\end{array}$ & Barley & Wheat & Apple & Sensitization \\
\cline { 2 - 4 } $\mathbf{1}$ & & IgE kU/L & & wheat products, nuts, beans \\
$\mathbf{2}$ & 1.2 & - & 6.4 & egg white \\
$\mathbf{3}$ & 9.8 & 33.1 & 25.6 & wheat products, nuts, beans \\
$\mathbf{4}$ & 15.8 & 14.3 & 14.4 & \\
$\mathbf{5}$ & - & - & 11.7 & apple, pear, carrot, pollen \\
$\mathbf{6}$ & 25.6 & 46.8 & 19.2 & peach, apple, pear, fish, meat \\
$\mathbf{7}$ & 9.5 & 17.8 & 0.9 & nuts, beans \\
$\mathbf{8}$ & 5.6 & 5.7 & 1.2 & grass pollen \\
$\mathbf{9}$ & 5.5 & 5.4 & 4.7 & fish \\
$\mathbf{1 0}$ & 6.4 & 2.9 & - & plum, dates \\
\hline & - & - & 11.5 & milk products, egg, nuts, beans \\
\hline
\end{tabular}

-: not determined.

Figure 2. The reactivity of sera IgE obtained from food allergic patients with proteins in barley extract. (A) SDS-PAGE pattern of molecular mass markers (a), $8 \mu \mathrm{g}$ of PBSextracted barley proteins (b), and $2 \mu \mathrm{g}$ of barley LTP (bLTP) (c). (B) Western blotting pattern of PBS-extracted barley proteins $(8 \mu \mathrm{g})$ with sera from food allergic patients (No. 1-10). IgE was visualized with alkaline phosphatase-conjugated anti-human IgE. The IgE characteristics of sera from allergic patients are shown in Table 1.

\section{(A)}

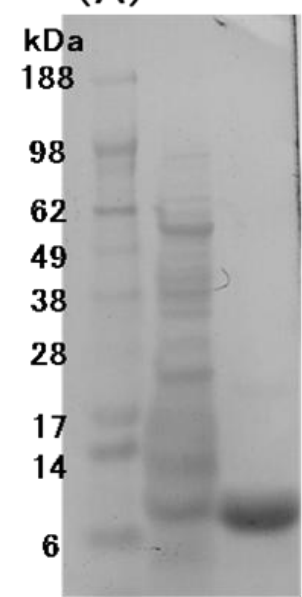

(a) (b) (c)
(B)

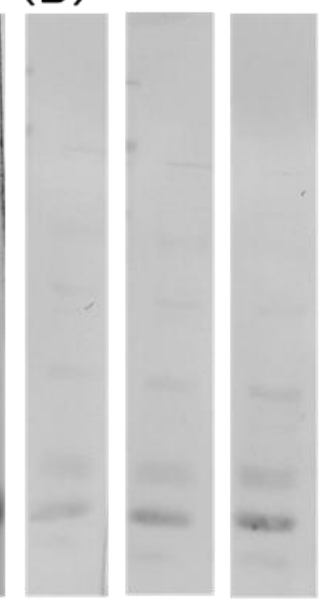

(1)
(2)
(3)

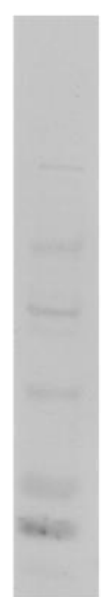

(4)

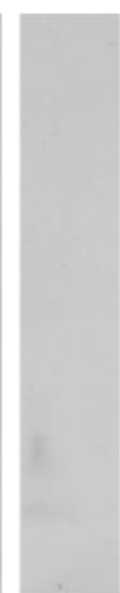

(5)

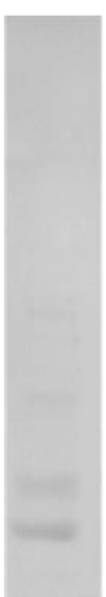

(6)

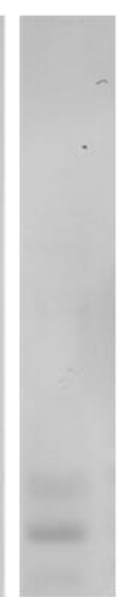

(7)

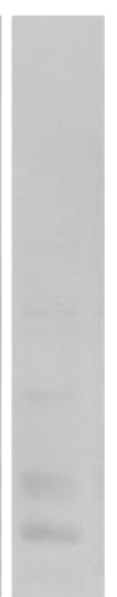

(8)

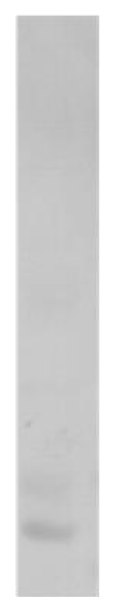

(9)

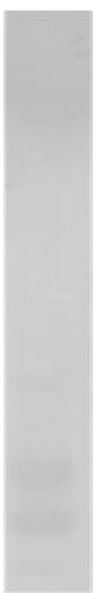

(10) 


\subsection{Preparation and Characterization of Monoclonal Antibodies to bLTP}

Thirteen mice were immunized with bLTP, and the spleen cells from mice showed high anti-bLTP titer were fused with myeloma cells. Four positive clones, 5-4, 10-1, 10-4, and 12-3 screened by an indirect ELISA possessed high specificity to bLTP. Using a mouse mAb isotyping kit, it was shown that the mAbs produced by these clones were all $\operatorname{IgG} 1 / \kappa$.

The specificity of these four anti-bLTP mAbs to LTP from other cereal grains was examined by immunoblotting analysis. After separation by SDS-PAGE, protein bands corresponding to LTP at around $9-\mathrm{kDa}$ were detected in extracts from barley, wheat, adlay, and rye (Figure 3A). Barley LTP was clearly detected by western blotting analysis with all four mAbs (Figure 3B-E). MAbs 5-4, 10-1, and 10-4 showed negative reactivity to the extracts from other sources. While, weak cross-reaction of mAb 12-3 with LTP from rye was observed (Figure 3E). The minor cross-reaction of mAb 12-3 with rye LTP might contribute to homologous amino acid sequences of its epitope in barley and rye. These mAbs exhibited no cross-reactivity against extracts from the major allergenic foods, such as eggs, milk peanuts, shrimp, and crab (data not shown). MAbs reactive with bLTP and their epitopes were previously revealed [29]. However, their cross-reactivity to other LTPs and application for quantitative analysis were unknown.

Figure 3. Cross reactivity of anti-bLTP monoclonal antibodies with other cereal grain LTPs. (A) SDS-PAGE pattern of molecular mass markers (a), $2 \mu \mathrm{g}$ of bLTP (b), and $8 \mu \mathrm{g}$ of PBS-extracted proteins from barley (1), wheat (2), adlay (3), and rye (4). (B-E) Western blotting pattern of PBS-extracted barley proteins $(8 \mu \mathrm{g})$ with various established anti-bLTP monoclonal antibodies (mAbs). (B), 5-4; (C), 10-1; (D), 10-4; (E) 12-3. =

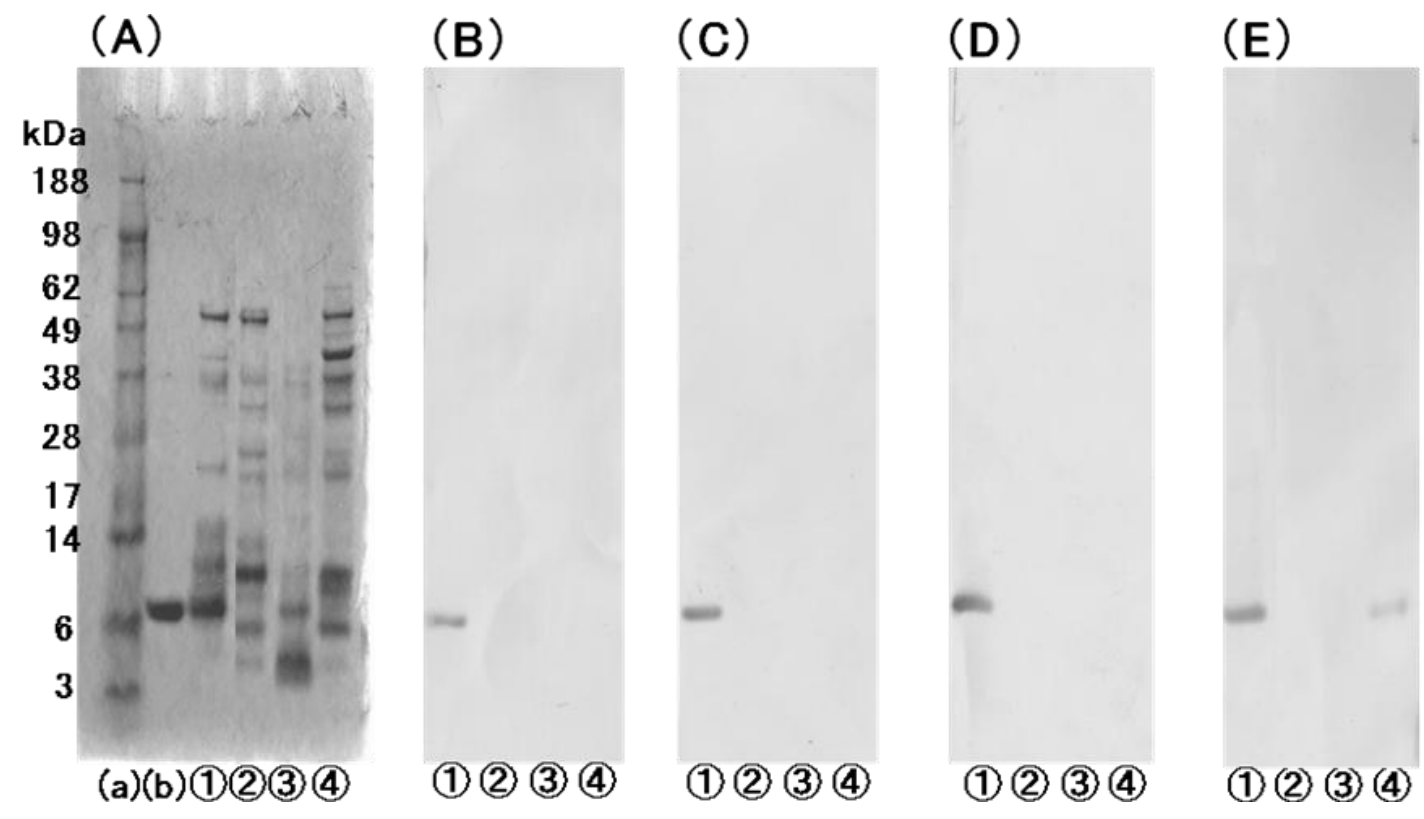

\subsection{Sandwich ELISA for the Determination of bLTP}

For the quantitative analysis of bLTP with high sensitivity, we developed sandwich ELISA systems with these mAbs. Each established mAb was used as the first antibody and peroxidase-conjugated 
counterparts were used as the second antibody. As shown in Figure 4, six different systems were capable of detecting bLTP. The system that uses mAb 10-4 as the first antibody and peroxidaseconjugated mAb 5-4 as the second antibody was identified as the highest sensitive system for bLTP quantitative analysis (Figure $4 \mathrm{C}$ ). The practical working range was $0.3-3 \mathrm{ng} / \mathrm{mL}$. The sensitivity of this system to wheat LTP was $1 / 300,000$ times less than that to bLTP (Figure 5). Thus, this sandwich ELISA system is significantly sensitive and specific to bLTP.

Figure 4. Sandwich enzyme-linked immunosorbent assays (ELISAs) for the quantitative analysis of bLTP. Sandwich ELISAs were constructed with mAb 5-4 (A), 10-1 (B), 10-4 $(\mathbf{C})$, or 12-3 (D) as a solid-phase antibody and peroxidase-conjugated mAb 5-4 (•), 10-1 (०), 10-4 ( $\mathbf{\Delta})$, or 12-3 $\triangle(\triangle)$ as a second antibody.
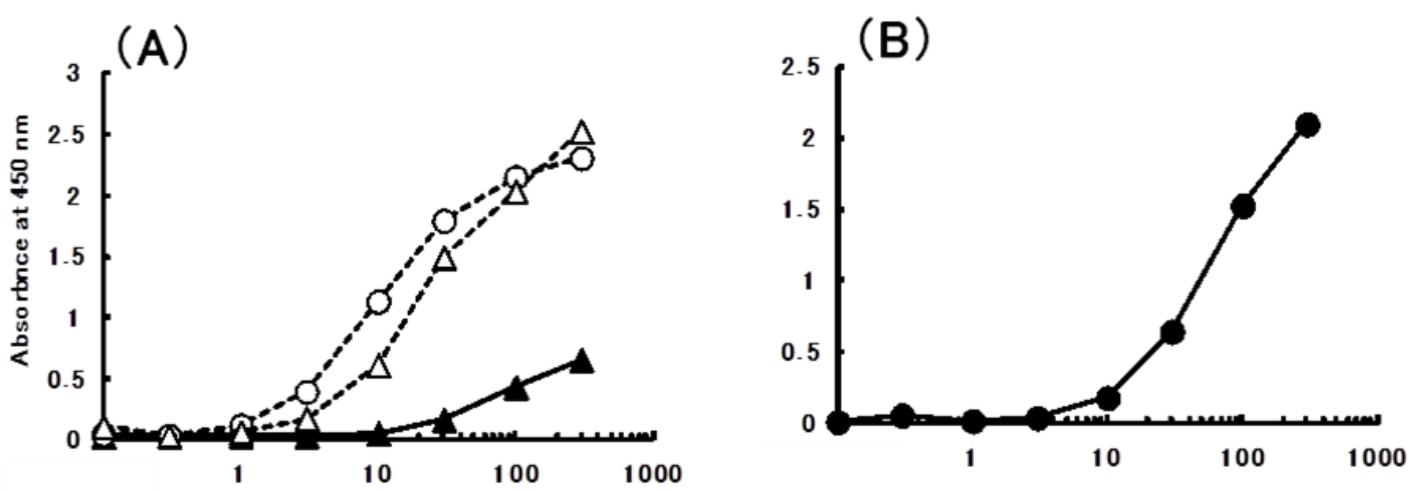

(C)
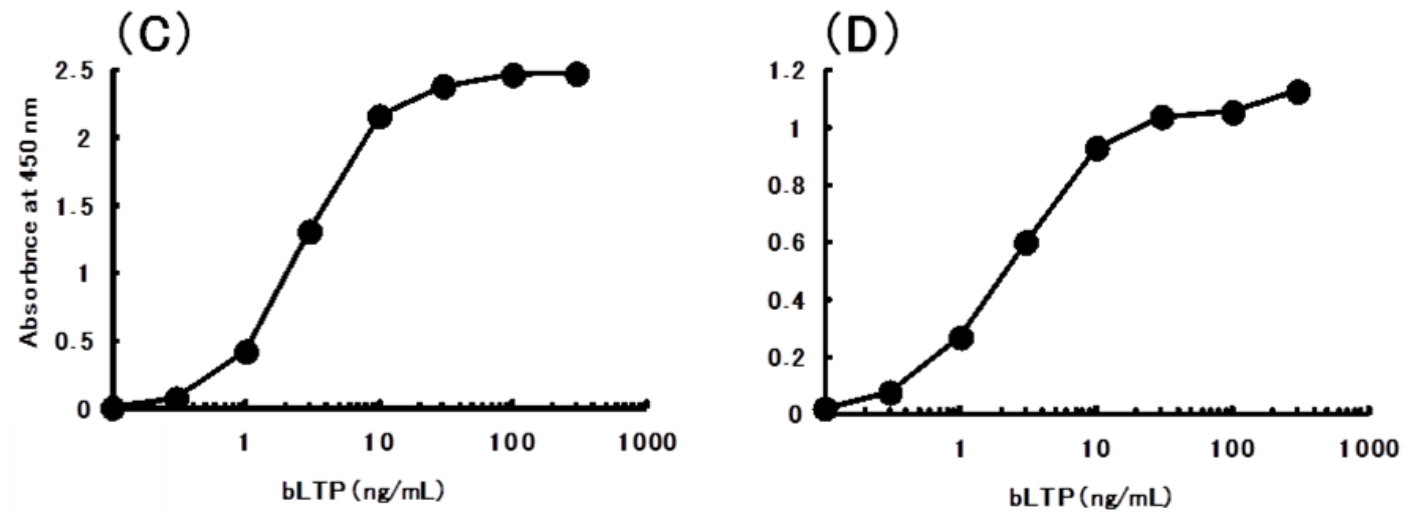

The 10-4/5-4 system was then applied for the determination of bLTP in several extracts prepared from barley or barley food products (Table 2). Barley is a major food and animal feed source. Two kinds of barley are widely used in food industry, two-row barley (Hordeum distichum) and six-row barley (Hordeum vulgare). The former from which we prepared bLTP is a traditional one for brewing, while the latter is used well as roasted barley grain, a raw material for a popular Asian tea. Comparable bLTP contents were obtained in the materials of both cultivars. However, bLTP could not be determined in leaf by this method probably due to the difference in amino acid sequence between grain and leaf LTP (Figure 1) [2]. Compared to those in raw materials, bLTP contents in processed barley foods were extremely low. In spite of stable structure of LTP suggesting high temperature tolerant characteristic, some denaturation of LTP at $96{ }^{\circ} \mathrm{C}$ was reported by Nierop et al. [23]. In addition, 
extraction efficiency might be lowered by heat-induced aggregation of components. Therefore, the low amount of bLTP detected in such processed barley foods could be contributed to these artificial factors. We have reported allergenicity of heat-denatured ovomucoid, a major egg allergen, which shows rigid conformation due to disulfide bonds and possesses heat stability similar to LTP [30]. Then, allergen had better to be estimated as total amounts irrespective of the degree of heat denaturation [31]. However, the 10-4/5-4 system showed several times lower reactivity to heated bLTP at $100{ }^{\circ} \mathrm{C}$ for 10 min than native bLTP (data not shown).

Figure 5. Reactivity of the 10-4/5-4 sandwich ELISA system to barley and wheat LTPs. Barley $(\bullet)$ or wheat LTP $(\circ)$ was determined by the sandwich ELISA, constructed with mAb 10-4 as a solid-phase antibody and peroxidase-conjugated mAb 5-4 as a second antibody.

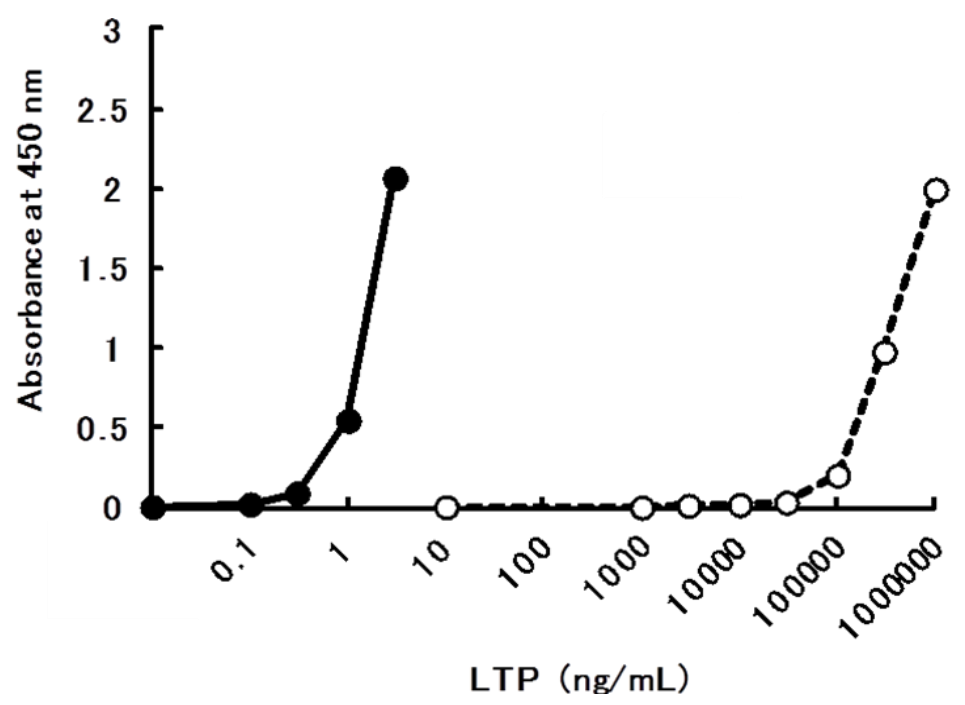

Table 2. Barley LTP content.

\begin{tabular}{cc}
\hline Food & $\mathbf{\mu g} / \mathbf{g}(\mathbf{m L})$ \\
\hline Two-row barley flower & 393.7 \\
Two-row barley flower & 301.3 \\
Barley leaf & - \\
Hattaiko $*$ & 0.1 \\
Roasted barley grain $* *$ & - \\
Barley miso *** & 18.3 \\
Malt vinegar & 21.0 \\
beer & 2.6 \\
\hline
\end{tabular}

-: not detected; * Roasted and grounded barley flour used for Japanese sweets; ** Raw material for popular Asian tea; *** Soybean paste made with barley malt.

ELISA screening is one of the official detection method to identify the allergenic ingredient in food by the Japanese official government [26]. Ovalbumin is selected as the target to detect egg, casein and $\beta$-lactoglobulin to detect milk, protein complex containing Ara h2 to detect peanut, and gliadin to detect wheat. In foods such as soybean paste, vinegar, and beer that wheat is used as one of the important ingredients, however, it is a serious problem that gliadin is hydrolyzed by proteolytic 
enzyme during fermenting process [32]. The fact that LTP is highly stable toward proteolysis attracted us an interest in utilization of wheat LTP as a substitute target protein in detection of wheat content in fermented food instead of gliadin [33]. In the same context, it was notable that bLTP was detected in fermented foods such as barley-malt miso, malt vinegar, and beer in Table 2.

\subsection{Quantitative Analysis of bLTP in Beer}

Barley LTP is a major proteinaceous component in beer [15,22-24]. Besides being an allergenic agent, it is also recognized as a foaming agent in brewing industry. Therefore, routine analysis of bLTP in product might be used to assist the quality controlling of beer production. In this study, we introduced the ELISA 10-4/5-4 system for assessing the quality of beer.

Three different brewing processes produce beers of the world. Bottom fermentation, generally used in production of beer in Japan, Germany, and the Netherlands, is performed at $4-13{ }^{\circ} \mathrm{C}$ for $4-6$ weeks. Beer is brewed at $20^{\circ} \mathrm{C}$ for two weeks in top fermentation, a brewing process widely used in United Kingdom and Belgium. Spontaneous fermentation, widely done in Belgium, is carried out with wild type yeast. Figure 6 shows that the amount of bLTP in beer samples was inconstant $(1-11 \mu \mathrm{g} / \mathrm{mL})$, independently of the brewing process and the producing country. Accordingly, variation in LTP contents is due to the difference in raw materials and detail of processing and might determine the character and quality of each beer.

Figure 6. Barley LTP levels in beer samples prepared by three different brewing processes. Concentration of bLTP was determined by the 10-4/5-4 sandwich ELISA system. I , bottom fermentation; II , top fermentation; III, spontaneous fermentation. No. 1-7, Japanese products; 8, English product; 9, German product; 10, Irish product; 11-17, Belgian products.

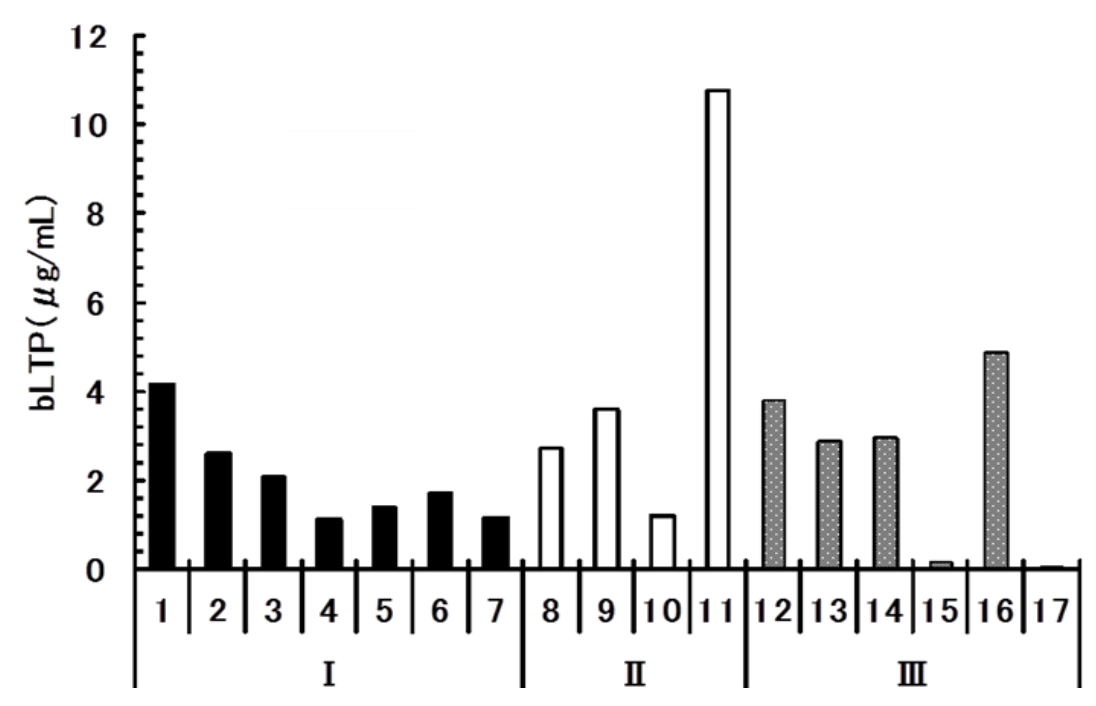

Four kinds of beer (A to D) manufactured in four different factory (1)-(4)) and different production days were monitored for bLTP level using the ELISA 10-4/5-4 system (Figure 7). All of the brewing processes in each factory had been performed perfectly in every day that the samples were taken. Analysis of the resultant beers indicated that there was no remarkable difference in the bLTP content of final products from different days in the same factory. The difference between bLTP content in beer from different lots of production is capable of being used to indicate the unusual producing condition 
such as quality of raw materials and is a good predictor of the different taste of beer. After the claim of a customer, a canned beer B was reported for induction of urticaria. However, this ELISA system failed to distinguish between bLTP content in beer of the claimed lot and that of other normal lots (Figure 7B, X). In default of any bizarreness in bLTP level, it is confirmed that the claimed lot of beer was produced by a proper brewing process. Thus, determining bLTP level in beer product by this ELISA gives valuable information for assuring the quality of beer to customer with little investment of time and money.

Figure 7. Comparison of bLTP content in beer between different lots of production. Four kinds of beers (A-D) produced in four different factories (1)-(4) and different days were obtained. The amount of bLTP was determined by the 10-4/5-4 sandwich ELISA system. (1) $10 / 1$ indicates that it was produced in factory (1) on October 1 st. (X) indicates the same lot product that was claimed by a customer.
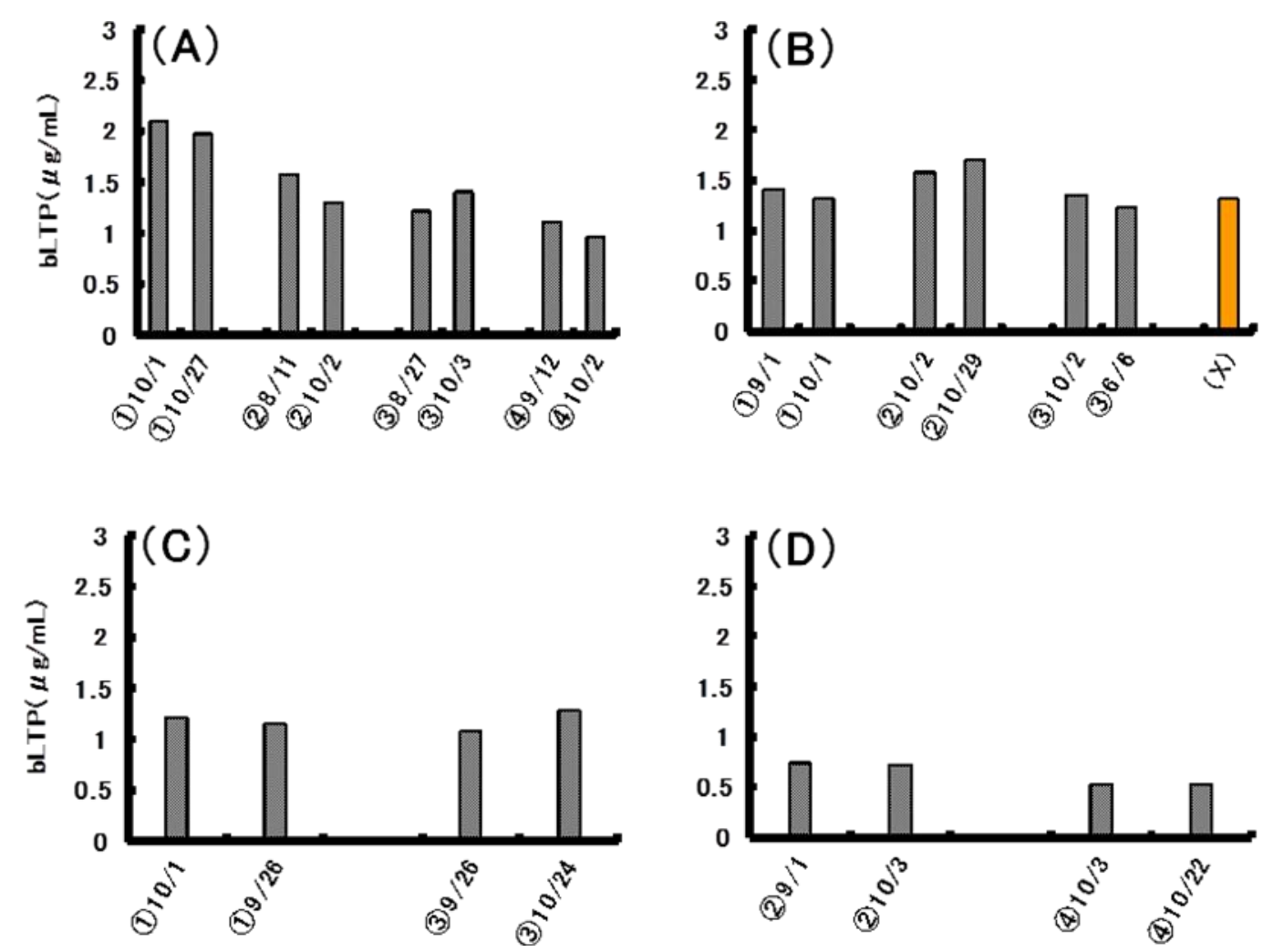

Controlling and monitoring bLTP content in beer is important, as bLTP is a factor for foam formation and stability and also as an allergen. This study introduces the sandwich ELISA using mAbs specific to bLTP as a useful tool for quality control and authenticity assessment of beer. Barley LTP determination by this ELISA might also be used to indicate the physical characteristic and taste of beer as well. For future experiment, the correlation of bLTP content in beer product with wort boiling temperature, fermenting method, addition of malt and brewing process will be determined. Moreover, bLTP might be indicated as a target protein in assessing of barley content in order to assist quality control of barley-fermented foods. Further information in application of bLTP in quality control system could provide the valuable information in novel product development in food and beverage industry. 


\section{Experimental Section}

\subsection{Reagents and Apparatus}

The following materials were obtained from the indicated sources: cell fusion and cell culture reagents, fetal bovine serum (FBS), and polyethylene glycol 1500 (Invitrogen, Carlsbad, California, USA), RPMI 1640 medium (Nacalai Tesque Inc., Kyoto, Japan), hypoxanthine thymidine (HT), hypoxanthine aminopterin thymidine (HAT) reagents and B cell growth factor, BriClone (Dainippon Pharmaceutical Co. Ltd., Osaka, Japan), Freund's complete and incomplete adjuvants (Difco Laboratories, Detroit, MI, USA), Protein G Sepharose and monoclonal antibody isotyping kit (GE Healthcare, Buckinghamshire, England), Maxisorp microplate for ELISA (Nunc, Roskilde, Denmark), $\mathrm{DC}^{\mathrm{TM}}$ protein assay kit (BIO-RAD laboratory, Bradford, UK), pristine (Sigma Chemical Corp, St. Louis, MO, USA), alkaline phoshatase-conjugated anti-mouse IgG and anti-human IgE (American Qualex, San Clemente, CA, USA). Sera from 10 patients allergic to food were supplied by PlasmaLab (Everett, WA, USA). Unless specified otherwise, all other chemicals used were guaranteed reagent grade.

\subsection{Isolation of Barley Grain LTP}

Barley grain flour ( $80 \mathrm{~g}$ ) was mixed with 3 fold volumes of water. The mixture was then stood overnight at room temperature. After centrifugation at $10,000 \times \mathrm{g}, 4{ }^{\circ} \mathrm{C}$ for $20 \mathrm{~min}$, the supernatant was collected as barley extract. Barley extract was further subjected to $\left(\mathrm{NH}_{4}\right)_{2} \mathrm{SO}_{4}$ fractional precipitation by adding $\left(\mathrm{NH}_{4}\right)_{2} \mathrm{SO}_{4}$ to $30 \%$ saturation, and then the pellet was discarded. Subsequently, $\left(\mathrm{NH}_{4}\right)_{2} \mathrm{SO}_{4}$ was added to the supernatant to $80 \%$. Following precipitation, the pellet was resuspended in $1.2 \mathrm{M}\left(\mathrm{NH}_{4}\right)_{2} \mathrm{SO}_{4}$. The $\mathrm{pH}$ of the solution was adjusted to 7.0 using $20 \mathrm{mM}$ phosphate buffer, beforehand, and this solution was applied to a Toyopearl butyl column $(2.5 \times 10 \mathrm{~cm})$ (Tosoh, Tokyo, Japan) equilibrated with $1.2 \mathrm{M}\left(\mathrm{NH}_{4}\right)_{2} \mathrm{SO}_{4}$. Proteins were eluted from the column by a linear gradient of 1.2 to $0 \mathrm{M}\left(\mathrm{NH}_{4}\right)_{2} \mathrm{SO}_{4}$. Relevant fractions were identified by the presence of a band at 9-kDa on sodium dodecyl sulphate-polyacrylamide gel electrophoresis (SDS-PAGE) gels under reduced condition. These fractions were pooled and dialyzed overnight against $20 \mathrm{mM}$ phosphate buffer, $\mathrm{pH}$ 5.0 (PB) using a dialysis tube (MWCO 3500 Da, Spectrum Laboratories, Rancho Dominguez, CA, USA). Then, the sample was applied to a Toyopearl CM column $(1.6 \times 5 \mathrm{~cm})$ (Tosoh, Tokyo, Japan) equilibrated with PB. Proteins were eluted with a linear gradient of 0 to $0.3 \mathrm{M} \mathrm{NaCl}$ in PB. LTP containing fractions were collected. The purity of protein was determined by SDS-PAGE. Purified LTP was dialyzed against water overnight, lyophilized, and stored at $-20{ }^{\circ} \mathrm{C}$, until use. Wheat LTP was purified as previously described [33]. Protein concentration was determined by $\mathrm{DC}^{\mathrm{TM}}$ protein assay using bovine serum albumin as a standard protein.

\subsection{Electrophoresis and Western Blotting}

SDS-PAGE was performed by the method of Laemmli [34] by using $10 \%$ gel. Sample was dissolved in $20 \mathrm{mM}$ Tris- $\mathrm{HCl}$ buffer ( $\mathrm{pH}$ 6.8) containing 2\% (w/v) SDS and $10 \mathrm{mM}$ 2-mercaptoethanol, and heated for $5 \mathrm{~min}$ in boiling water. After electrophoresis, the gel was stained with Commassie Brilliant Blue R-250. The protein with molecular mass of 9-kDa was identified as LTP. 
Extracts from barley, wheat, adlay, and rye, with $8 \mu \mathrm{g}$ protein content, were applied to gel electrolysis. After been performed on SDS-PAGE, the proteins in a gel were transblotted to a polyvinylidene difluoride (PVDF) membrane. The membrane was transferred to a blocking solution (PBS containing $5 \%$ skim milk) for $60 \mathrm{~min}$, and then incubated with the anti-bLTP mAb at room temperature for $1 \mathrm{~h}$. After washing with $10 \mathrm{mM}$ Tris buffer, $\mathrm{pH} 7.4$ containing $0.15 \mathrm{M} \mathrm{NaCl}$ (TBS) several times, the membrane was incubated with alkaline phosphatase-conjugated anti-mouse IgG at room temperature for $1 \mathrm{~h}$. After extensively washing again with TBS, protein band on the membrane was developed with alkaline-phosphatase kit. When human sera were tested, alkaline phosphatase-conjugated anti-human $\operatorname{IgE}$ was used.

\subsection{N-Terminal Amino Acid Sequencing}

The N-terminal amino acid sequence of purified LTP electrophoretically transferred to a PVDF membrane was analyzed by Edman degradation using Applied Biosystem Procise 491 HT Protein Sequencer (Foster City, CA, USA). The amino acid sequence obtained was compared with that of bLTP in public database.

\subsection{Production of Monoclonal Antibody}

Thirteen eight-week old female BALB/c mice (Nippon SLC Co., Shizuoka, Japan) were immunized by intraperitoneal injection of $100 \mu \mathrm{g}$ of bLTP emulsified in Freund's complete adjuvant. At two and four weeks after the initial immunization, the mice were boosted by intraperitoneal injection of $50 \mu \mathrm{g}$ of bLTP emulsified in Freund's incomplete adjuvant. The final booster was given by intraperitoneal injection of $10 \mu \mathrm{g}$ LTP in $10 \mathrm{mM}$ phosphate buffer, $\mathrm{pH} 7.4$ containing $0.15 \mathrm{M} \mathrm{NaCl}$ (PBS) at the sixth week. On the third day after the final injection, the spleen cells were harvested from the mice and then fused with the mouse myeloma cell (P3U1) [35]. Fused cells were seeded in 96-well culture plates and incubated at $37{ }^{\circ} \mathrm{C}$ in HAT medium. After 2 weeks in a $\mathrm{CO}_{2}$ incubation, the culture supernatant of each hybridoma was examined for reactivity with bLTP by an indirect ELISA. Hybridoma from the well that perform high reactivity with antigen were subcloned twice by limiting dilution on HT medium containing 5\% BriClone. Each clone secreting antibody to bLTP was grown in mass culture. Subclass of immunoglobulin in culture supernatant of each clone was identified by a mouse mAb isotyping kit. Cloned cells were injected intraperitoneally into a 10 -week old mouse treated with pristine. The monoclonal antibody was purified by using a protein $G$ affinity column from the ascitic fluid. The purified antibody was conjugated with horseradish peroxidase [36]. Animal experiments were carried out under the guideline of Animal Experiment Committee of Kyoto Women's University following the bulletin (No.71, 2006) of the Ministry of Education, Culture, Sports, Science, and Technology in Japan.

\subsection{Preparation of Extract for LTP Determination}

Milled cereal grain powder $(1 \mathrm{~g})$ was briefly homogenized with $19 \mathrm{~mL}$ PBS. After being shaken overnight, the homogenate was centrifuged at $3,000 \times \mathrm{g}, 4{ }^{\circ} \mathrm{C}$ for $20 \mathrm{~min}$. The supernatant was collected and further filtrated through a filter paper No.2. The clear filtrate was used as cereal grain extract to determine the LTP content in further experiment. There was no special treat for beer sample. 


\subsection{Enzyme-Linked Immunosorbent Assay (ELISA)}

For indirect ELISA, each well of 96-well flat-bottom polystyrene microplate was coated with $50 \mu \mathrm{L}$ per well of $2 \mu \mathrm{g} / \mathrm{mL}$ bLTP. After overnight incubation at $4{ }^{\circ} \mathrm{C}$, the unbound site was blocked by incubation with $200 \mu \mathrm{L}$ per well of blocking reagent (10\% BSA in PBS) at $37{ }^{\circ} \mathrm{C}$ for $1 \mathrm{~h}$. Media fluid of hybridoma culture $(50 \mu \mathrm{L})$ was added into wells and incubated at $37^{\circ} \mathrm{C}$ for $1 \mathrm{~h}$. After washing with TBS containing $0.02 \%$ tween 20 (TBS-T), $100 \mu \mathrm{L}$ of anti-mouse $\mathrm{IgG}$ conjugated to alkaline phosphatase diluted in TBS-T containing $0.1 \%$ BSA was added and incubated at $37{ }^{\circ} \mathrm{C}$ for $1 \mathrm{~h}$. After washing, $100 \mu \mathrm{L}$ of chromogenic substrate $\left(1 \mathrm{mg} / \mathrm{mL} \rho\right.$-nitrophenylphosphate and $0.5 \mathrm{mM} \mathrm{MgCl}_{2}$ in $10 \%$ diethanlamine buffer, $\mathrm{pH}$ 9.8) was added and incubated at $37{ }^{\circ} \mathrm{C}$ for $1 \mathrm{~h}$. The intensity of the resulting color was detected at $415 \mathrm{~nm}$ by a microplate reader. For sandwich ELISA, each well of the plate was coated with $50 \mu \mathrm{L}$ of $5 \mu \mathrm{g} / \mathrm{mL}$ of anti-bLTP mAb in coating buffer at $37{ }^{\circ} \mathrm{C}$ for $1 \mathrm{~h}$. After blocking and three washing, $50 \mu \mathrm{L}$ of barley extract $(0-100 \mathrm{ng} / \mathrm{mL})$ or beer sample was add to each well of the coated plate, and incubated at $37{ }^{\circ} \mathrm{C}$ for $1 \mathrm{~h}$. Then, to each washed well $50 \mu \mathrm{L}$ of peroxidase-conjugated anti-bLTP mAb was added. After incubated at $37{ }^{\circ} \mathrm{C}$ for $1 \mathrm{~h}$, the substrate solution was added, developed, and finally the absorbance at $450 \mathrm{~nm}$ was measured as described above.

\section{Conclusions}

A sandwich-type of enzyme-linked immunosorbent assay was developed with mouse monoclonal antibodies raised against LTP purified from barley grain flour. LTP is known to be a factor in foam formation and stability in beer, while also being an allergen. This method was then proposed as a predominant system for the quality control of beer.

\section{Acknowledgements}

The authors thank Mayuko Mishima, Chie Iguchi, and Saori Shibata of Department of Food and Nutrition, Kyoto Women's University for their helpful technical assistance.

\section{Conflict of Interest}

The authors declare no conflict of interest.

\section{References and Notes}

1. Kader, J.C. Lipid-transfer proteins in plants. Annu. Rev. Plant Physiol. Plant Mol. Biol. 1996, 47, 627-654.

2. Douliez, J.P.; Michon, T.; Elmorjani, K.; Marion, D. Structure, biological and technological functions of lipid transfer protein and indolines, the major lipid binding protein from cereal kernels. J. Cereal Sci. 2000, 32, 1-20.

3. Garcia-Olmedo, F.; Molina, A.; Segura, A.; Moreno, M. The defensive role of nonspecific lipid-transfer proteins in plants. Trends Microbiol. 1995, 3, 72-74.

4. Kader, J.C. Lipid-transfer proteins: A puzzling family of plant proteins. Trends Plant Sci. Biol. 1997, 2, 66-70. 
5. Hincha, D.K. Cryoprotectin: A plant lipid- transfer protein homologue that stabilized membranes during freezing. Philos. Trans. R. Soc. Lond. B. Biol. Sci. 2002, 357, 909-919.

6. Gaudet, D.; Laroche, A.; Frick, M.; Huel, R.; Puchalski, B. Cold induced expression of plant defensin and lipid transfer protein transcripts in winter wheat. Physiol. Plant 2003, 117, 195-205.

7. Bubier, J.; Schlappi, M., Cold induction of EARLI1, a putative Arabidopsis lipid transfer protein, is light and calcium dependent. Plant Cell Environ. 2004, 27, 929-936.

8. Gorjanović, S.; Sužnjević, D.; Beljanski, M.; Ostojić, S.; Gorjanović, R.; Vrvić, M.; Hranisavljević, J. Effects of lipid-transfer protein from malting barley grain on brewers yeast fermentation. J. Inst. Brew. 2004, 110, 297-302.

9. Sohal, A.K.; Pallas, J.A.; Jenkins, G.I. The promoter of a Brassica napus lipid transfer protein gene is active in a range of tissues and simulated by light and viral infection in transgenic Arabidopsis. Plant Mol. Biol. 1999, 41, 75-87.

10. Park, C.J.; Shin, R.; Park, J.M.; Lee, G.J.; You, J.S.; Paek, K.H. Induction of pepper cDNA encoding a lipid- transfer protein during the resistance response to tobacco mosaic virus. Plant Mol. Biol. 2002, 48, 243-254.

11. Zasloff, M. Antimicrobial peptides of multicellular organisms. Nature 2002, 415, 389-395.

12. Van Loon, L.; Van Strien, E. The families of pathogenesis-related proteins, their activities, and comparative analysis of PR-1 type proteins. Physiol. Mol. Plant Pathol. 1999, 55, 85-97.

13. Sanchez-Monge, R.; Lombardero, M.; Garcia-Selles, F. J.; Barber, D.; Salcedo, G. Lipid-transfer proteins are relevant allergen in fruit allergy. J. Allergy Clin. Immunol. 1999, 103, 514-519.

14. Palacin, A.; Cumplido, J.; Figueroa, J.; Ahrazem,O.; sanchez-Monge, R.; Carrillo, T.; Salcedo, G.; Blanco, C. Cabbage lipid transfer protein Bra o 3 is major allergen responsible for cross-reactivity between plant foods and pollens, J. Allergy Clin. Immunol. 2006, 117, 1423-1429.

15. Curioni, A.; Santucci, B.; Cristaudo, A.; Canistraci, C.; Pietravalle, M.; Simonato, B.; Giannattasio, M. Urticaria from beer: An immediate hypersensitivity reaction due to a $10 \mathrm{kDa}$ protein derived from barley. Clin. Exp. Allergy 1999, 29, 407-413.

16. Pastrorello, E.A.; Farioli, L.; Pravettoni, V.; Robino, A.M.; Scibilia, J.; Fortunato, D.; Conti, A.; Borgonovo, L.; Bengtsson, A.; Ortolani, C. Lipid transfer protein and vicilin are important walnut allergens in patients not allergic to pollen. J. Allergy Clin. Immunol. 2004, 114, 908-914.

17. Hiller, K.M.; Lubahan, B.C.; Klapper, D.G. Cloning and expression of ragweed allergen Amb a 6, Scand. J. Immunol. 1998, 48, 26-36.

18. Charvolin, D.; Douliez, J.P.; Marion, D.; Cohen-Addad, C.; Pebay-Peyroula, E. The crystal structure of a wheat nonspecific lipid transfer protein (ns-LTP1) complexed with two molecules of phospholipids at $2.1 \AA$ resolution. Eur. J. Biochem. 1999, 264, 562-568.

19. Lerche, M.H.; Poulsen, F.M. Solution structure of barley lipid transfer protein complexed with palmitate. Two different binding modes of palmitate in the homologous maize and different nonspecific lipid transfer protein. Protein Sci. 1998, 7, 2490-2498.

20. Salcedo, G.; Sanchez-Monge, R.; Diaz-Perales, A.; Garcia-Casado, G.; Barber, D. Plant non-specific lipid transfer proteins as food and pollen allergens. Clin. Exp. Allergy 2004, 34, 1336-1341.

21. Salcedo, G.; Diaz-Perales, A.; Sanchez-Monge, R. Fruits allergy: Plant defence protein as noval potential panallergen. Clin. Exp. Allergy 1999, 29, 1158-1160. 
22. Lindroff-Larsen, K.; Winther, J.R. Surprisingly high stability of barley lipid transfer protein, LTP1, towards denaturant, heat and proteases. FEBS Lett. 2001, 488, 145-148.

23. Van Nierop, S.N.E.; Evans, D.E.; Axcel, B.C.; Cantrell, I.C.; Rautenbach, M. Impact of different wort boiling temperatures on the beer foam stabilizing properties of lipid transfer protein 1. J. Agric. Food Chem. 2004, 52, 3120-3129.

24. Garcia-Casado, G.; Crespo, J.F.; Rodriguez, J.; Salcedo, G. Isolation and charasterization of barley lipid transfer protein and protein $\mathrm{Z}$ as beer allergens. J. Allergy Clin. Immunol. 2001, 108, 647-649.

25. Quercia O; Zoccatelli, G; Stefanini, GF; Mistrello, G; Amato, S; Bolla, M; Emiliani, F; Asero, R. Allergy to beer in LTP-sensitized patients: Beers are not all the same. Allergy 2012, 67, 1186-1189.

26. Akiyama, H.; Imai, T.; Ebisawa, M. Japan food allergen labeling regulation-History and Evaluation. In Advances in Food and Nutrition Research; Taylor, S., Ed.; Academic Press: Burlington, MA, USA, 2011; Volume 62, pp. 139-171.

27. Lowry, O.H.; Rosebrough, N.J.; Farr, A.L.; Randall, R.J. Protein measurement with the Folin phenol reagent. J. Biol. Chem. 1951, 193, 265-275.

28. Van Paridon, P. A.; Gadella, T.W.J., Jr.; Wirtz, K.W.A. The effect of polyphosphoinositides and phosphatidic acid on the phosphatidylinositol transfer protein from bovine brain: Kinetic study. Biochim. Biophys. Acta 1988, 943, 76-86.

29. Lusk, L.T.; Navarro, A.L.; Goldstein, H.; Wagner, R.J.; Ryder, D.S. Monoclonal antibodies for assaying lipid transfer proteins. U.S. Patent 6423546, 23 July 2002.

30. Hirose, J.; Kitabatake, N.; Kimura, A.; Narita, H. Recognition of native and/or thermally induced denatured forms of the major food allergen, ovomucoid, by human IgE and mouse monoclonal IgG antibodies. Biosci. Biotechnol. Biochem. 2004, 68, 2490-2497.

31. Hirose, J.; Murakami-Yamaguchi, Y.; Ikeda, M.; Kitabatake, N.; Narita, H. Oligoclonal enzymelinked immunosorbent assay capable of determining the major food allergen, ovomucoid, irrespective of the degree of heat denaturation. Cytotechnology 2005, 47, 145-149.

32. Honjoh, T.; Muraoka, S.; Mamekoshi, S.; Sakai, M. Detection methods for allergic substances in foods by enzyme linked immune sorbent assay. Foods Food Ingredients J. Jpn. 2002, 206, 13-22.

33. Murakami-Yamaguchi, Y.; Hirose, J.; Honjoh, T.; Narita, H. Evaluation of wheat content with monoclonal antibodies against lipid transfer protein. J. Jpn. Soc. Food Ssi. Technol. 2009, 56, 16-24.

34. Laemmli, U.K. Cleavage of structural proteins during the assembly of the head of bacteriophage T4. Nature 1970, 227, 680-685.

35. Kohler, G.; Milstein, C. Continuous cultures of fused cells secreting antibody of predefined specificity. Nature 1975, 256, 495-497.

36. Nakane, P.K.; Kawaoi, A. Perioxidase-labelled antibody. New method of conjugation. J. Histochem. Cytochem. 1974, 22, 1084-1091.

(C) 2012 by the authors; licensee MDPI, Basel, Switzerland. This article is an open access article distributed under the terms and conditions of the Creative Commons Attribution license (http://creativecommons.org/licenses/by/3.0/). 